\title{
Avaliação da qualidade bacteriológica da água utilizada para abastecimento público no município de Pelotas - RS - Brasil
}

\author{
Evaluation of water bacteriological quality used for public supply in the city of \\ Pelotas - RS - Brazil
}

\author{
Greice Hartwig Schwanke Peil ${ }^{* 1}$, Anelise Vicentini Kuss ${ }^{2}$ e \\ Maria do Carmo Ferreira Gonçalves ${ }^{3}$ \\ ${ }^{1,2}$ Institto de Biologia - Dep. de Microbiologia e Parasitologia - Universidade Federal de Pelotas - RS Brasil \\ ${ }^{3}$ Universidade Federal do Rio Grande do Sul- RS Brasil
}

\begin{abstract}
Resumo
A água é recurso natural indispensável à vida, e sua contaminação constitui um grande risco a saúde pública, além de provocar diversos problemas ambientais. O presente trabalho teve como objetivo avaliar a presença de Pseudomonas aeruginosa, coliformes totais e Escherichia coli, na água de abastecimento público do município de Pelotas-RS. Foram coletadas 12 amostras de água bruta e 12 de água tratada na Estação de Tratamento de Água Santa Bárbara. A análise de P. aeruginosa foi realizada pela técnica de tubos múltiplos, e a detecção de coliformes totais e E. coli, pelo método do substrato cromogênico (Fluorocult e Colilert). Das amostras de água bruta, 91,7\% revelaram crescimento de P. aeruginosa, E. coli, e 100\% foram positivas para coliformes totais. As amostras de água coletadas após o tratamento não apresentaram nenhum crescimento bacteriano. Os resultados obtidos indicam que o sistema de tratamento foi eficaz na eliminação de bactérias indesejáveis e patogênicas. Portanto, a água tratada distribuída em Pelotas atende aos parâmetros bacteriológicos estabelecidos pela legislação.
\end{abstract}

Palavras-chave: Qualidade da água. Avaliação bacteriológica. Pseudomonas aeruginosa. Coliformes totais. Escherichia coli.

\begin{abstract}
Water is a natural resource essential for life and their contamination are a major risk to public health, in addition to causing many environmental problems. This study aimed to evaluate the presence of Pseudomonas aeruginosa, total coliforms and Escherichia coli, from water to public supply of the city of Pelotas/RS. Twelve samples of raw water and twelve of treated water were collected at the Santa Barbara's Water Treatment Station. Analysis for P. aeruginosa was realized by multiple tube technique, and detection of total coliforms and E. coli was realized by chromogenic substrate method (Fluorocult and Colilert). About raw water samples, $91.7 \%$ indicated growth of $P$. aeruginosa, E. coli, and $100 \%$ of samples presented positive contamination by total coliforms. Samples of water collected after the treatment did not show any bacterial growth. Results indicate that the treatment system was effective to eliminate the undesirable and pathogenic bacterial. Therefore, the treated water distributed in Pelotas complies with bacteriological parameters established by legislation.
\end{abstract}

Keywords: Water quality. Evaluation bacteriological. Pseudomonas aeruginosa. Total coliforms. Escherichia coli. 


\section{Introdução}

$\mathrm{A}$ A água constitui um importante recurso natural, indispensável a manutenção da vida no planeta. A quantidade e a qualidade da água potável estão diretamente relacionadas com a saúde humana, devido a sua utilização para o consumo, higiene e produção de alimentos. O monitoramento dos recursos hídricos é fundamental, pois a poluição destes ambientes abrange uma série de fatores como, presença de substâncias nocivas e tóxicas que levam a alteração das características químicas, físicas e biológicas do meio (CORADI et al., 2009).

Entre as principais fontes de contaminação estão o esgoto sem tratamento, aterros sanitários, defensivos agrícolas, produtos químicos e resíduos tóxicos que são depositados em ambientes aquáticos (OKURA; SIQUEIRA, 2005). A crescente poluição e a contaminação dos mananciais resultam na transmissão de muitos agentes infecciosos, causadores de doenças diarreicas, responsáveis por um elevado número de mortes nos países em desenvolvimento, incluindo o Brasil (OLIVEIRA et al., 2012). Entre as principais doenças originadas pela água contaminada estão, a cólera, febre tifóide, leptospirose e giardíase (SANTOS et al., 2013), e os agentes biológicos de maior importância são as bactérias, protozoários, vírus e os helmintos, provenientes principalmente de contaminação fecal humana e animal, em águas destinadas ao consumo (CARDOSO et al., 2007).

A Organização Mundial de Saúde (OMS) estabeleceu alguns critérios para qualidade da água potável, dentre elas, avaliação microbiológica quanto a presença de bactérias indicadoras de contaminação fecal, pela contagem de bactérias do grupo coliformes. Porém, outras bactérias podem estar presentes em águas de abastecimento, muitas patogênicas e multirresistentes, como do gênero Pseudomonas, encontradas no solo, na água e matéria orgânica em decomposição e podem ser isoladas da pele, garganta e fezes de pessoas doentes. A espécie $P$. aeruginosa é um importante patógeno oportunista $e$ apresenta resistência à diversos antibióticos (CORR $\hat{E} A$ et al., 2013).

A presença de coliformes totais e de coliformes termotolerantes em ambiente aquático indica contaminação fecal da água e risco da presença de organismos patogênicos, responsáveis pela transmissão das principais doenças infecciosas. No grupo de coliformes termotolerantes, a principal espécie é a Escherichia coli, que ocorre exclusivamente no trato intestinal do homem $e$ animais homeotérmicos (OKURA; SIQUEIRA, 2005). Sendo considerada como indicador de qualidade da água, com maior especificidade para avaliar contaminação fecal recente e indicar a possível ocorrência de bactérias patogênicas no ambiente (SILVA et al., 2005).

No Brasil a Portaria $n^{\circ} 2.914$ de 12 de dezembro de 2011 do Ministério da Saúde estabelece as normas sobre o padrão de potabilidade e qualidade da água para consumo humano, onde são apresentados valores máximos permitidos para as características microbiológicas, organolépticas, físicas e químicas. A água potável é definida como: "água apropriada para o consumo humano e cujos indicadores biológicos, microbiológicos, físicos, químicos e radioativos, atendem ao padrão de potabilidade, sem oferecer riscos à saúde", portanto, quanto ao padrão microbiológico, a água deve estar isenta de coliformes totais e termotolerantes, inclusive E. coli, em amostras de $100 \mathrm{~mL}$ (BRASIL, 2011).

O objetivo do trabalho foi avaliar a presença de Pseudomonas aeruginosa, coliformes totais e Escherichia coli, em um reservatório de água e na respectiva estação de tratamento de água de distribuição pública no município de Pelotas-RS.

\section{Materiais e Métodos}

\subsection{Amostragem}

Foram coletadas 12 amostras de água bruta e 12 de água tratada em frascos de vidro de $100 \mathrm{~mL}$, a cada sete dias durante 70 dias. As coletas de água foram realizadas na Estação de Tratamento de Água (ETA) Santa Bárbara, município de Pelotas, localizada aproximadamente a $3 \mathrm{Km}$ da área urbana. Esta ETA foi construída para complementar o abastecimento de água potável da cidade, utilizando as águas da barragem construída a partir do fechamento do Arroio Santa Bárbara (SANEP, 2014). Segundo o Serviço Autônomo de Saneamento de Pelotas (SANEP) a ETA têm a capacidade total de 40 milhões de litros diários, responsável pelo abastecimento de diversos pontos da cidade como, Centro, Zona do Porto, Bairro Navegantes, Vila Fátima, Bairro Fragata, Distrito Industrial e Vila COHAB.

O Departamento de Tratamento do SANEP realiza o tratamento da água bruta para consumo através do método convencional, que consiste nas etapas de coagulação e floculação, decantação, filtração, desinfecção, fluoretação e neutralização do $\mathrm{pH}$.

\subsection{Análise de Pseudomonas aeruginosa}

A pesquisa de $P$. aeruginosa foi realizada através do método de tubos múltiplos, descrito por Silva et al. (2005), sendo inoculados $10 \mathrm{~mL}$ de amostra em 10 tubos contendo $10 \mathrm{~mL}$ de Caldo Asparagina em dupla concentração. Após a incubação a $37^{\circ} \mathrm{C}$ por 48 horas, foi realizada a confirmação de tubos positivos através do desenvolvimento de coloração esverdeada, confirmada pelo aparecimento de fluorescência quando submetidos a luz ultravioleta em câmara escura. Os tubos positivos foram repicados para placas contendo Ágar Cetrimide, meio específico para $P$. aeruginosa, e incubadas a $37^{\circ} \mathrm{C}$ por 48 horas. Através da leitura em tabela NMP (Número Mais Provável), o resultado obtido indicou a quantidade de P. aeruginosa para $100 \mathrm{~mL}$ de amostra. As colônias típicas (brancas ou esverdeadas) foram repicadas para placas com Ágar Leite e incubadas a $37^{\circ} \mathrm{C}$ por 48 horas. O crescimento de colônias esverdeadas e aparecimento de halo claro em torno da colônia, resultado da hidrólise da caseína, confirma a presença de $P$. aeruginosa.

2.3 Análise de coliformes totais e Escherichia coli As análises de coliformes totais e E. coli foram realizadas pelo 
método do substrato cromogênico, segundo APHA (1998). Para amostras de água bruta, a determinação foi realizada pela técnica de tubos múltiplos, utilizando meio de cultura comercial Fluorocult巴. Foram transferidos $1 \mathrm{~mL}, 0,1 \mathrm{~mL} e$ $0,01 \mathrm{~mL}$ de amostra em 5 tubos de ensaio nas diluições $10^{\circ}$, $10^{-1}$ e $10^{-2}$, respectivamente, e foram incubados a $37^{\circ} \mathrm{C}$ por 24 horas. Após, foi realizada a contagem de tubos positivos, os quais atingiram a coloração verde-azulada, em cada uma das diluições. Para E. coli foi realizada a contagem, sendo considerado como positivo, os tubos que apresentaram fluorescência azulada no caldo, observados sob luz ultravioleta em câmara escura. Os resultados para coliformes totais e E. coli foram descritos através da leitura em tabela NMP, informando a quantidade de cada grupo bacteriano em 100 mL de água.

Para água tratada, foi utilizado meio de cultura comercial Colilert®. Foi realizada a diluição de um sachê em $100 \mathrm{~mL}$ de amostra, incubou-se por 24 horas a $37^{\circ} \mathrm{C}$. Os tubos que apresentaram coloração amarela escura, foram considerados positivos na avaliação de coliformes totais e aqueles que apresentaram fluorescência azulada sob luz ultravioleta, revelaram presença de E. coli.

\section{Resultados e Discussão}

\subsection{Análise bacteriológica da água bruta}

$\mathrm{Na}$ tabela 1. podem ser visualizados os resultados obtidos na avaliação das 12 amostras de água bruta. Foi constatada a presença de $P$. aeruginosa em 11 amostras, apresentando entre 1,1 e 6,9 NMP/100 $\mathrm{mL}^{-1}$ de água, correspondendo a 91,7\% das amostras. Na avaliação quanto a presença de coliformes totais, todas as amostras se apresentaram positivas, variando de 170 a $7900 \mathrm{NMP} / 100 \mathrm{~mL}^{-1}$ de água. No caso da presença de E. coli, foram observadas 11 amostras positivas (91,7\% das amostras), variando entre 20 e $330 \mathrm{NMP} / 100 \mathrm{~mL}^{-1}$ de água, exceto em uma amostra, que apresentou $1300 \mathrm{NMP} / 100 \mathrm{~mL}$ ${ }^{-1}$ de água bruta.

$\mathrm{Na}$ primeira coleta de água houve um maior índice de contaminação por coliformes totais e E. coli (7900 e 1300 NMP/100 $\mathrm{mL}^{-1}$, respectivamente) enquanto $P$. aeruginosa apresentou um baixo indice. Neste caso, não foi observado uma relação entre a contagem de coliformes totais e E. coli com $P$. aeruginosa, visto que a maior contaminação por $P$. aeruginosa foi detectado nas coletas 6 e 9.

A contagem de P. aeruginosa realizada na água bruta pode ser visualizada na Figura 1.

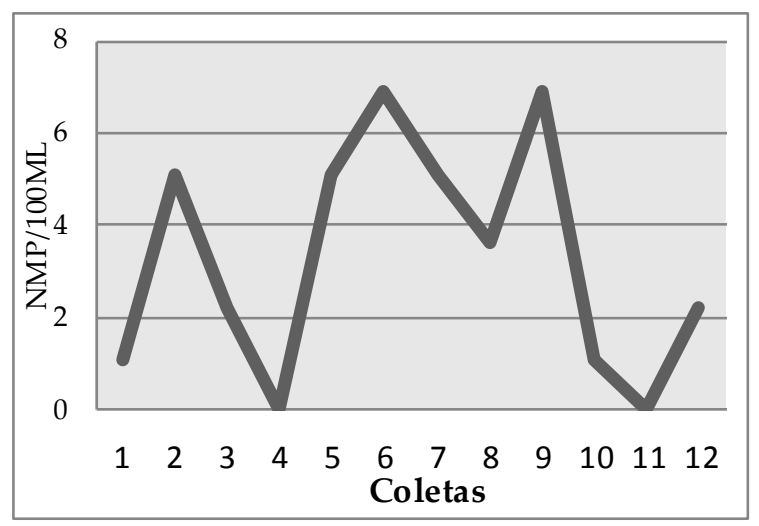

Figura 1: Contagem de Pseudomonas aeruginosa na água bruta utilizada para abastecimento do município de Pelotas, RS.

A bactéria $P$. aeruginosa pode ser observada em água com baixos níveis de sólidos dissolvidos e compostos orgânicos, evidenciando sua habilidade adaptativa aos ambientes com baixa disponibilidade de nutrientes (GUERRA et al., 2006). Sendo patogênica e com propriedades de resistência, faz com que seja uma das principais bactérias causadoras de infecções hospitalares (SADER et al., 2001). Estas infecções

Tabela 1: Avaliação bacteriológica da água bruta captada na Estação de Tratamento de Água de Pelotas - RS.

\begin{tabular}{cccc}
\hline Coletas & $\begin{array}{c}\text { Pseudomonas aeruginosa } \\
(\mathrm{NMP} / 100 \mathrm{~mL})\end{array}$ & $\begin{array}{c}\text { Coliformes Totais } \\
(\mathrm{NMP} / 100 \mathrm{~mL})\end{array}$ & $\begin{array}{c}\text { Escherichia coli } \\
(\mathrm{NMP} / 100 \mathrm{~mL})\end{array}$ \\
\hline 1 & 1,1 & 7900 & 1300 \\
2 & 5,1 & 790 & 330 \\
3 & 2,2 & 790 & 140 \\
4 & 0 & 790 & 45 \\
5 & 5,1 & 790 & 140 \\
6 & 6,9 & 3300 & 330 \\
7 & 5,1 & 260 & 20 \\
8 & 3,6 & 170 & 20 \\
9 & 6,9 & 260 & 20 \\
10 & 1,1 & 790 & 0 \\
11 & 0 & 3300 & 330 \\
12 & 2,2 & 2200 & 330
\end{tabular}


acometem diversos sítios do corpo humano de pacientes imunocomprometidos (FUENTEFRIA et al., 2008). O sistema respiratório é o mais frequente, levando ao desenvolvimento de pneumonia, também provoca infecções do trato urinário e corrente sanguínea, entres outras (FERRAREZE et al., 2007). Apesar dos riscos que essa bactéria apresenta à saúde, a legislação atual não apresenta parâmetro algum para $P$. aeruginosa, referente a água in natura e a água tratada destinada ao consumo humano. Somente para a água engarrafada, a espécie é apresentada como parâmetro, na Resolução $n^{\circ}$ 275, de 22 de setembro de 2005 da Agência Nacional de Vigilância Sanitária (ANVISA, 2005).

A água bruta captada na ETA de Pelotas apresentou má qualidade, segundo as análises microbiológicas, devido a presença das bactérias. Sendo assim, verificou-se que a água utilizada para o abastecimento da população, antes do tratamento, está contaminada. Essa contaminação se confirma através da verificação do alto percentual $(91,7 \%)$ de amostras positivas para P. aeruginosa e E. coli, bem como $100 \%$ das amostras positivas para coliformes totais. Segundo Amaral et al. (2003) a contaminação dos ecossistemas aquáticos superficiais está diretamente relacionada com os poluentes carreados pelo deflúvio superficial. Poluentes ou substâncias que podem modificar as características físico-químicas e biológicas, inclusive microbiológicas, alterando a qualidade dos mananciais.

Os resultados revelam uma baixa contagem de P. aeruginosa e E. coli em relação aos coliformes totais. O grupo de coliformes totais inclui bactérias de origem entérica e ambiental. Tanto os coliformes totais quanto a E. coli, pertencente aos coliformes termotolerantes, indicam contaminação fecal do ambiente. A maioria das bactérias pertencentes ao grupo de coliformes termotolerantes incluem os gêneros Escherichia, Enterobacter, Citrobacter e Klebsiella, além de outros (SILVA et al., 2005). Estes são causadores de doenças e E. colié

indicadora de risco da presença de outros micro-organismos patogênicos. A bactéria E. coli, apresenta alguns sorotipos causadores de gastroenterites, que provocam diarreia (CORDEIROet al., 2004).

Apesar dos insatisfatórios resultados bacteriológicos da água bruta, conforme a Resolução 357/05 do Ministério da Saúde, a água coletada pode ser classificada como classe I. Neste estudo, segundo a tabela 1, as amostras que revelaram contagem de E. coli acima do limite atingiram um percentual de $41,67 \%$, o que permite classificá-la em classe I. Nesta classe, a contagem de coliformes termotolerantes ou de E. Coli não deve ultrapassar de 200 UFC/100 mL de água amostrada.

Os resultados obtidos neste estudo são semelhantes a, outros estudos, que confirmam que água in natura, sem o devido tratamento, pode apresentar altos níveis de micro-organismos perigosos à saúde humana. O estudo de Amaral et al. (2003) na região Nordeste de São Paulo, avaliou 180 amostras de água utilizada para consumo, quanto a presença de coliformes totais, E. coli e número de micro-organismos mesófilos, em 30 propriedades rurais. Como resultado, $90 \%$ das amostras de água das fontes, 90\% dos reservatórios e 96,7\% de consumo humano, coletadas em período chuvoso, e 83,3\%, 96,7\% e
$90 \%$, daquelas coletadas respectivamente nos mesmos locais, durante período de seca, não estavam em conformidade com os padrões microbiológicos de potabilidade, caracterizando fator de risco à população.

Okura e Siqueira (2005) analisaram amostras de água de minas (sem tratamento), e como resultado, em 99,67\% das águas foi detectado a presença de coliformes totais e termotolerantes, evidenciando que as águas estavam impróprias para o consumo humano. Moura et al. (2009) avaliaram a qualidade da água de oito minas utilizadas pela população de Uberaba (MG), e constataram que $75 \%$ delas apresentaram-se impróprias para consumo, principalmente pela presença de coliformes fecais. Santos et al. (2010) avaliaram a qualidade microbiológica da água em dois mananciais que abastecem Goiânia (GO), antes e após o tratamento em ETAs municipais. Como resultado um dos rios apresentou maior nível de contaminação fecal, porém a água tratada apresentou qualidade satisfatória, não sendo detectados coliformes ou Salmonella spp, em ambos locais.

\subsection{Análise bacteriológica da água tratada}

Entre as alíquotas de água tratada não foi detectada nenhuma das bactérias avaliadas, atendendo os parâmetros microbiológicos estabelecidos pela legislação. A qualidade da água é determinada segundo especificações do Ministério da Saúde, que estabelece como padrão de potabilidade para água destinada ao consumo humano, a ausência de bactérias dos grupos coliformes totais e E. coli em $100 \mathrm{~mL}$ de água. Portanto, quanto ao parâmetro microbiológico, a água tratada do município de Pelotas pode ser considerada própria para o consumo humano e sem riscos à saúde da população.

Segundo a OMS, a ausência dos coliformes totais constitui um indicador adequado e suficiente na avaliação da eficiência do tratamento, visto que eles apresentam uma taxa de decaimento similar ou superior à dos coliformes termotolerantes, incluindo a E. coli. A ausência da bactéria E. coli na água tratada, indica que não há contaminação fecal, nem outros patógenos. Portanto o processo de tratamento empregado em Pelotas levou a destruição elou remoção das bactérias avaliadas.

Segundo a Portaria $n^{\underline{0}}$ 2.914/2011, além do padrão microbiológico, a água para ser considerada potável deve atender aos padrões de: turbidez para água pós-filtração ou pré-desinfecção, substâncias químicas que representam risco à saúde, cianotoxinas na água, radioatividade, padrão organoléptico, monitoramento de cianobactérias no manancial de abastecimento.

Apesar dos resultados satisfatórios para água tratada, deve ser realizado um monitoramento constante desta água na ETA, bem como avaliar a qualidade da água que chega ao consumidor. Visto que do tratamento ao consumo, uma série de fatores pode comprometer a qualidade dessa água tratada. Dentre os fatores podem-se destacar as condições de segurança dos reservatórios de distribuição, a falta de manutenção na rede de distribuição (vazamentos, limpeza e descarga periódica), a intermitência do abastecimento que pode gerar riscos de contaminação na rede e as condições de armazenamento domiciliar da água. 
Resultados semelhantes aesteestudo são descritos na literatura. Bettega et al. (2006) constataram a ausência de coliformes totais e fecais em amostra de água após o tratamento realizado pela Companhia de Saneamento do Paraná (SANEPAR) Curitiba-PR. Cruz et al. (2009) avaliaram 15 amostras de água em estabelecimentos da educação infantil da rede pública do Gama (DF), todas próprias para o consumo, ausentes de coliformes termotolerantes. Entretanto, outros estudos realizados em diferentes regiões do País não apresentam um tratamento considerado eficiente para águas de abastecimento. $A$ avaliação da qualidade da água para abastecimento público em dois bairros do Município de Nova Iguaçu (RJ), desenvolvido por $D^{\prime}$ Aguila et al. (2000) revelou que 61\% das amostras de água tratada apresentaram coliformes e $P$. aeruginosa, evidenciando que $61,51 \%$ dos pontos coletados estavam contaminados, indicando que o tratamento da água não foi eficaz. Alves et al. (2002) analisaram 18 amostras de água de abastecimento, obtidas na área urbana e de diferentes localidades do município de Marília (SP), e constataram a presença de coliformes.

Guerra et al. (2006) analisaram 413 amostras de água potável do sistema principal e do sistema secundário em Bandeirantes (PR). Destas, 10,41\% estavam contaminadas por P. aeruginosa, incluindo $23,53 \%$ das amostras do sistema de água secundário, e 8,56\% das amostras do sistema de água principal, porém nenhuma amostra apresentou contagem de bactérias do grupo coliforme. O estudo de Cardoso et al. (2007) em Salvador (Bahia), com amostras de água coletadas em 83 escolas, revelou que 41\% das amostras apresentaram contaminação por coliformes totais e termotolerantes, sendo essa água imprópria para o consumo.

Siqueira et al. (2010) avaliaram a qualidade bacteriológica de 40 amostras de água de consumo, em diferentes unidades de alimentação de Recife (PE), e como resultado $62,5 \%$ das amostras apresentaram contaminação por coliformes totais $e$ $42,5 \%$ das amostras contaminadas por termotolerantes, não atendendo os padrões de potabilidade da legislação.

\section{Conclusões}

O sistema de tratamento na Estação de Tratamento de Água do município de Pelotas é eficaz na eliminação de bactérias indesejáveis e patogênicas, visto que anteriormente ao tratamento apresentava uma contagem elevada. De acordo com os resultados a água distribuída à população é de boa qualidade, pois não foram constatadas contaminações por $P$. aeruginosa, coliformes totais e E. coli nas amostras de água tratada testadas. Apesar dos resultados satisfatórios, a água destinada para o consumo humano deve ser avaliada, de forma frequente, quanto a qualidade microbiológica.

\section{Referências}

Agência Nacional de Vigilância Sanitária (ANVISA). Resolução RDC n 275 de 22 de setembro de 2005.
Regulamento técnico de características microbiológicas para água mineral natural e água natural. Diário Oficial da União, 23 set. 2005.

ALVES, N. C.; ODORIZZI, A. C.; GOULART, F. C. Análise microbiológica de águas minerais e de água potável de abastecimento, Marília, SP. Revista de Saúde Pública, São Paulo, v. 36, n. 6, p. 749-751, 2002.

AMARAL, L. A.; FILHO, N. A.; ROSSI JR., O. D.; FERREIRA, F. L. A.; BARROS, L. S. S. Água de consumo humano como fator de risco à saúde em propriedades rurais. Revista de Saúde Pública, São Paulo, v. 37, n. 4, p. 510-514, 2003.

American Public Health Association (APHA). Standard Methods for The Examination of Water and Wastewater. 20ª ed. Washington, 1998.

BETTEGA, J. M. P. R.; MACHADO, M. R.; PRESIBELLA, M.; BANISKI, G.; BARBOSA, C. A. Métodos analíticos no controle microbiológico da água para consumo humano. Ciência e Agrotecnologia, Lavras, v. 30, n. 5, p. 950-954, 2006.

BRASIL. Portaria no 2.914 de 12 de Dezembro de 2011. Dispõe sobre os procedimentos de controle e de vigilância da qualidade da água para consumo humano e seu padrão de potabilidade. Diário Oficial da União. 12 dez. 2011.

CARDOSO, R. C. V.; ALMEIDA, R. C. C.; GUIMARÃES, A. G.; GOES, J. A. W.; SILVA, A. S.; SANTANA, A. A. C.; HUTTNER, L. B.; VIDAL JR., P. O.; FIGUEIREDO, K. V. N. A. Qualidade da água utilizada em escolas atendidas pelo Programa Nacional de Alimentação Escolar (PNAE), em Salvador-BA. Revista Instituto Adolfo Lutz, São Paulo, v. 66, n. 3, p. 287-291, 2007.

Conselho Nacional do Meio Ambiente (CONAMA). Resolução № 357 de 17 de março de 2005. Dispõe sobre a classificação dos corpos de água e diretrizes ambientais para o seu enquadramento, bem como estabelece as condições e padrões de lançamento de efluentes, e dá outras providências. Diário Oficial da União, 18 mar. 2005.

CORADI, P. C.; FIA, A. R.; PEREIRA-RAMIREZ, O. Avaliação da qualidade da água superficial dos cursos de água do município de Pelotas-RS, Brasil. Revista Ambiente \& Água, Taubaté, v. 4, n. 2, p. 46-56, 2009.

CORDEIRO, A. C. S.; LEITE, S. G. F.; DEZOTTI, M. Inativação por oxidação fotocatalítica de Escherichia coli e Pseudomonas sp. Química Nova, São Paulo, v. 27, n. 5, p. 689-694, 2004. 
CORRÊA, T. C. S.; DUARTE, H. A.; LOURENÇO, E. A.; RIBEIRO, G. J.; SILVA, L. F.; MEDEIROS, J. R. C.; SOUZA, N. C. P.; PEREIRA, C. A. S. Avaliação da População Microbiana Presente no Interior do Corpo das Torneiras de uma UTI em um Hospital no Município de Volta Redonda. Cadernos UniFOA, Rio de Janeiro, n. 1, p. 17-21, 2013.

CRUZ, J. B. F.; CRUZ, M. A. S.; RESENDE, A. Análise microbiológica da água consumida em estabelecimentos da educação infantil da rede pública do Gama, DF. Revista de Saúde e Biologia, v. 4, n. 1, p. 21-23, 2009.

D' AGUILA, O. S.; ROQUE, O. C. C.; MIRANDA, C. A. S.; FERREIRA, A. P. Avaliação da qualidade de água para abastecimento público do Município de Nova Iguaçu. Cadernos de Saúde Pública, Rio de Janeiro, v. 16, n. 3, p. 791-798, 2000.

FERRAREZE, M. V. G.; LEOPOLDO, V. C.; ANDRADE, D.; SILVA, M. F. I.; HAAS, V. J. Pseudomonas aeruginosa multirresistente em unidade de cuidados intensivos: desafios que procedem?*. Acta Paulista de Enfermagem, São Paulo, v. 20, n. 1, p. 7-11, 2007.

FUENTEFRIA, D. B.; FERREIRA, A. E.; GRAF, T.; CORÇÃO, G. Pseudomonas aeruginosa: disseminação de resistência antimicrobiana em efluente hospitalar e água superficial. Revista da Sociedade Brasileira de Medicina Tropical, Uberaba, v. 41, n. 5, p. 470473, 2008.

GUERRA, N. M. M.; OTENIO, M. H.; SILVA, M. E. Z.; GUILHERMETTI, M.; NAKAMURA, C. V.; UEDANAKAMURA, T.; FILHO, B. P. D. Ocorrência de Pseudomonas aeruginosa em água potável. Acta Scientiarum Biological Sciences, Maringá, v. 28, n. 1, p. 13-18, 2006.

MOURA, R. S.; PELLI, A.; TERRA, A. P. S.; OKURA, M. H. Qualidade da água de minas em área urbana na cidade de Uberaba (MG). Revista Baiana de Saúde Pública, Salvador, v. 33, n. 2, p. 231-242, 2009.

OKURA, M. H.; SIQUEIRA, K. B. Enumeração de coliformes totais e coliformes termotolerantes em água de abastecimento e de minas. Revista de Higiene Alimentar, São Paulo, v. 19, n. 135, p. 86-91, 2005.

OLIVEIRA, D. V.; SILVA, T. C.; ZANIN, J. G.; NACHTIGALL, G.; MEDEIROS, A. W.; FRAZZON, A. P. G.; VANDER SAND, S. T. Qualidade da água e identificação de bactérias gram-negativas isoladas do arroio dilúvio, Porto Alegre, Rio Grande do Sul, Brasil. Evidência, Joaçaba, v. 12, n. 1, p. 51-62, 2012.
SADER, H. S.; GALES, A. C.; PFALLER, M. A.; MENDES, R. E.; ZOCCOLI, C.; BARTH, A.; JONES, R. N. Pathogen Frequency and Resistance Patterns in Brazilian Hospitals: Summary of Results from Three Years of the SENTRY Antimicrobial Surveillance Program. Brazilian Journal of Infectious Diseases, Salvador, v. 5, n. 4, p. 200-214, 2001

SANTOS, P. P.; MIRANDA, T. M. T.; BARTHASSSON, D. L.; SOUZA, K. M. C.; BRITO, W. M. E. D.; ANDRÉ, M. C. D. P. B.; SERAFINI, A. B. Qualidade microbiológica de afluentes e efluentes de estações de tratamento de água e esgoto de Goiânia, Goiás. Revista de Patologia Tropical, Goiás, v. 39, n. 3, p. 173-187, 2010.

SANTOS, J. O.; SANTOS, R. M. S.; GOMES, M. A. D.; MIRANDA, R. C.; NÓBREGA, I. G. M. A qualidade da água para o consumo humano: Uma discussão necessária. Revista Brasileira de Gestão Ambiental, Pombal, v. 7, n. 2, p. 19-26, 2013.

Serviço Autônomo de Saneamento de Pelotas (SANEP). Disponível em: <http://www.pelotas.rs.gov.br/sanep/ estacoes-de-tratamento/>. Acesso em: 22 fev. 2014.

SILVA, N.; NETO, R. C.; JUNQUEIRA, V. C. A.; SILVEIRA, N. F. A. Manual de Métodos de Análise Microbiológica de Água. São Paulo: Varela, 2005.

SIQUEIRA, L. P.; SHINOHARA, N. K. S.; LIMA, R. M. T.; PAIVA, J. E.; FILHO, J. L. L.; CARVALHO, I. T. Avaliação microbiológica da água de consumo empregada em unidades de alimentação. Ciência e Saúde Coletiva, Rio de Janeiro, v. 15, n. 1, p. 63-66, 2010. 